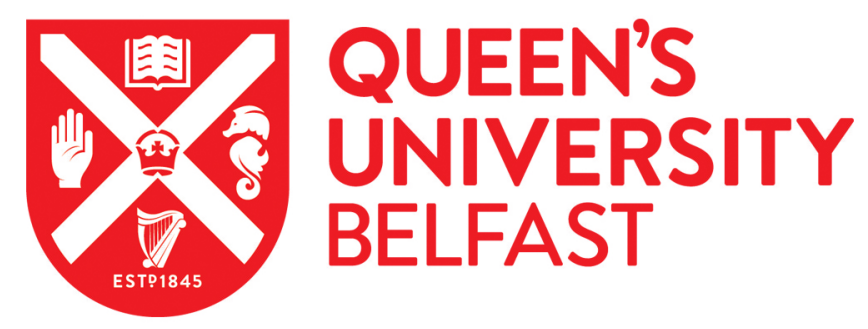

\title{
Waiting for International Political Sociology: A Field Guide to Living In- Between
}

Lisle, D. (2017). Waiting for International Political Sociology: A Field Guide to Living In-Between. International Political Sociology, 10(4), 417-433. https://doi.org/10.1093/ips/olw023

\author{
Published in: \\ International Political Sociology
}

Document Version:

Peer reviewed version

Queen's University Belfast - Research Portal:

Link to publication record in Queen's University Belfast Research Portal

\section{Publisher rights}

Copyright ( 2017 International Studies Association

This is a pre-copyedited, author-produced version of an article accepted for publication in International Political Sociology following peer review. The version of record Lisle, D 2017, 'Waiting for International Political Sociology: A Field Guide to Living In-Between' International Political Sociology, vol 10, no. 4, pp. 417-433 is available online at: https://academic.oup.com/ips/article-lookup/doi/10.1093/ips/olw023

\section{General rights}

Copyright for the publications made accessible via the Queen's University Belfast Research Portal is retained by the author(s) and / or other copyright owners and it is a condition of accessing these publications that users recognise and abide by the legal requirements associated with these rights.

\section{Take down policy}

The Research Portal is Queen's institutional repository that provides access to Queen's research output. Every effort has been made to ensure that content in the Research Portal does not infringe any person's rights, or applicable UK laws. If you discover content in the Research Portal that you believe breaches copyright or violates any law, please contact openaccess@qub.ac.uk. 


\section{Learning How To See}

Debbie Lisle

One of the most gratifying moments in intellectual life is when an interlocutor - often a colleague, collaborator, student, audience member or friend - responds to your work with the words "I see!" It is a moment of clarity and understanding when the usually fraught exercise of communication is suddenly transparent: I see where you are coming from; I see your point of view; and most importantly, I see something I haven't seen before. This is the moment you discover a comrade who sees the same world that you do and who has found inspiration in your idiosyncratic, disparate and often incoherent thoughts; in short, you are not alone. This is how communities and movements begin; more specifically, this is how the diverse group of scholars and students gathering around the ideas behind international political sociology began. ${ }^{1}$ We found each other and acknowledged our shared interests with resounding affirmations: "I see!"; "I get it!"; and "Me too!" Tentative explorations (e.g. "do you see the world this way as well?") became collectively and confidently shared as multiple visions connected and gathered momentum.

With that spirit of solidarity in mind, I want to open up the simple phrase "I see!" to explore the multiple ways that visuality underscores our work around an international political sociology. Certainly I am not suggesting that all of our work in that emergent field of study has a visual component, nor do I think it should. Nor am I suggesting that visuality means only the act of looking at and analysing visual images - clearly it entails much more than this. As Steve Graham argues, 'the power of the visual always exceeds the simple matter of representation' (2010: 202). Rather, I am interested in how the central questions of visuality are driven by the same questions that underscore international political sociology; namely, how power is mobilized, consolidated and dispersed in ways that entrench and sometimes subvert global asymmetries. More specifically, I am interested in how the central questions of visuality - who does the seeing and who does not; who / what is being seen and who / what is rendered invisible; who is the assumed audience; what is privileged in the enframed world and what is not; how does the construction and arrangement of visual content produce a preferred meaning - can be useful tools in opening up the constitutive power relations of, for example, a site, an event, a document, a region, a conflict, a disaster or an institution. In short, what interests me is how central questions of visuality can inform the research agenda in international political sociology in productive, creative and critical ways.

This chapter draws from a number of literatures to outline the main components and parameters of visuality that align with the central concerns of an international political sociology. It then goes on to explore the three main approaches to visuality that scholars identifiable with the field of international political sociology have so far pursued, highlighting the work of key thinkers and some of the key methods, developments and controversies. Along the way, I will reflect on my own struggles using visuality and suggest what I have found to be the most productive aspects of each approach.

\section{What we mean when we see the world}

Exploring how visuality has emerged within and through an international political sociology requires an engagement with, and understanding of, at least four registers of knowledge production. Firstly, and most comprehensively, seeing always entails the related registers of being, knowing and 
becoming. In this sense, seeing performs an act of empirical confirmation - it reassures us that we exist within a world 'out there', and that this co-constitutive relation may well continue into the future. As Mike Crang suggests, visuality always implies a much deeper understanding of being:

envisioning is a way of being-towards the world. It is not a case of pictures showing what is 'out there', nor indeed what is 'in here', but rather how objects are made to appear for us. It is a way in which the world is apprehended as picturable, it is 'enworlded' by being enframed. In this sense images are not so much counterposed to reality as a route through which worlds are created (Crang, 1997: 362; see also Jay, 1994).

Crang makes two crucial points here: images are not separate from the world 'out there', and any act of envisioning is necessarily political because it involves framing. The co-constitution of reality and representation, as well as the inclusions and exclusions produced by acts of framing, are central to the way scholars engaging with an international political sociology have explored the ontological and epistemological claims of visuality. Our work in this regard has been especially enlivened by Jacques Rancière's exploration of how politics resides in the partition of the sensible - in the forces that produce and subsequently manage what becomes visible, intelligible and present and what does not $(2006 ; 2009)$. Judith Butler has also explored how these ontological partitions are governed by dominant visual and narrative frames that constitute what is representable in the first place, and therefore who counts as human and ultimately grievable in times of war (2010). In all of these explorations power is absolutely central; that is, seeing and being always entail associated and often violent productions of invisibility and absence.

Second, seeing is always about subjectivity - about who is empowered by seeing and who is objectified by being seen. Seeing is integral to modern forms of subjectivity because it implies a vantage point (point-of-view) and a horizon within which other subjects, objects and trajectories can be positioned. As we know from decades of critical scholarship, of course, when the viewer is positioned as the generator of that epistemological landscape (and therefore outside of its perspective), he/she remains in a position of privilege vis-à-vis that world and its contents. In this sense, logics of seeing / being seen are always logics of power that privilege the subject position of the viewer and subordinate those Others who are plotted within its horizon. Scholars that focus on the visual interconnections between the international, the political and the sociological are best placed to critique the figure of the rational, seeing subject with an omnipresent, neutral or objective point-of-view, and track the many consequences that arise from privileging such a figure.

Third, the landscapes generated by privileged modern viewers are located in global spaces; that is, visuality has a particular geopolitics. Here, the interdisciplinary space between International Relations, Geography and Geopolitics has been particularly productive in showing how our visualizations of global space reproduce powerful and familiar asymmetries (Campbell, 2007; Hughes, 2007; Fraser, Hughes \& Dodds, 2010) Within an international political sociology, it is not surprising that those modern subjects so often in charge of viewing practices are located in privileged global spaces such as the networked urban centres of Europe, North America and the Anglophone world. Unlike traditional IR which is burdened by (obsessed with?) sovereignty, recent work in international political sociology has pursued questions of scale in promising ways, for 
example, showing how asymmetrical global relations are reproduced in satellite images just as they are reproduced in intimate, domestic settings (Bissell, 2009; Grondin, 2011; Shim, 2013).

Fourth, the asymmetrical character of these geopolitically grounded logics of seeing / being seen did not emerge spontaneously; indeed, these relations are historically constituted by long-standing structural and global inequalities. For me, the most powerful accounts of this history of visuality draw from postcolonial scholarship to show how an 'imperial gaze' has been constantly invoked by privileged subjects to produce, visually locate and ultimately control 'native' populations (Landau \& Kaspin, 2002; Pratt, 1992; Ryan, 1997). While the asymmetry underscoring the entwined history of Orientalism, empire and visuality seems overwhelming, Nicholas Mirzoeff has articulated a powerful case for counter-visuality by showing how those abject and objectified Others constantly being visualized by privileged subjects have always returned the gaze of the master (2011). This work is important because it encourages more critical genealogies that uncover the subjugated 'views from below' in order to trouble, disaggregate and re-work dominant logics of seeing / being seen. More recently, some of the most exciting work in international political sociology has re-directed genealogical approaches away from the past and the present to show how particular futures are being visualized in ways that reproduce current logics of asymmetrical rule (Amoore, 2009; Aradau \& Van Munster, 2012).

These four registers of knowledge production do not remain as disaggregated as I have suggested here, nor are they all addressed by scholarship combining in international political sociology and visuality. Indeed, there are many cross-pollinations, juxtapositions and tensions within this intellectual field that take scholars into exciting new transdisciplinary terrains. What I mean to suggest here is that work on visuality within an international political sociology operates broadly within a similar ethical, political and critical field that enables scholars to foreground how power relations are produced through seeing / being seen logics. To provide a flavour of that field, I have categorized the studies of visuality within an international political sociology into three broad approaches.

\section{Seeing Through Images: The Representational Register}

The critical turn in IR in the early 1990s produced two related trajectories. While some scholars applied a critical lens to familiar foreign policy documents and canonical texts to reveal constitutive exclusions, fantasies and performances (Campbell, 1992; Der Derian \& Shapiro, 1989; Weber, 1995), others looked for mobilizations of sovereignty, authority and violence outside of these official registers. And it is here, in this second trajectory, that visual culture emerged as a legitimate source and expression of global politics. Following the lead of Michael Shapiro (1984; 1988), scholars travelled into a whole new transdisciplinary world as they found visual expressions of global power in very unfamiliar places (e.g. films, photographs, art installations, television, advertising). Certainly much of this work aligned with scholars in IR who were critically exploring textual based documents through various forms of discourse analysis; indeed, my own studies of visual culture grew out of a prior study of travel writing (Lisle, 2006a). One of the most productive tensions that arose in this early work was how literary, textual and rhetorical documents differed from visual, photographic and cinematic ones. Could discourse analysis simply be applied to visual documents? Or did they constitute a representative field that was qualitatively different? Indeed, some of the debates within security studies expressed disagreement as to whether texts and images operated in the same way 
to 'securitize' new domains (Hansen, 2011; Williams, 2003). Similarly, there are interesting tensions between the so-called 'cultural' and 'aesthetic' turns within IR as to where exactly visual analysis resides (Bleiker, 2001; 2009; Salter \& Mutlu, 2012; Sylvester, 2009).

These debates have been particularly fruitful in terms of energizing scholarship on visuality within an international political sociology. Researchers no longer have to spend their time justifying how and why visual representations are legitimate sources of 'evidence' as there are more scholarly communities and intellectual spaces where this starting place is accepted. ${ }^{2}$ Some of the strongest aspects of this work have been theoretical and conceptual as scholars are asking difficult empistemological, ontological, ethical, political and material questions about the way visuality is geopolitically and globally significant. David Campbell's work on sighting / siting the Darfur conflict is certainly important here, as are studies on the visual co-ordinates of violence, pain and pity (Campbell, 2007; Dauphinée, 2007; Hutchinson, 2014; Möller, 2013). Other scholars, including myself, have offered more detailed analyses of how global power relations emerge in specific modes of visual representation, for example, film, television, photography and art (Danchev, 2009; Kiersey \& Neumann, 2013; Lisle, 2007, 2010; Möller, 2010; Shapiro, 2008; Weldes, 2003). All this has produced an exciting and widespread interest in how visual culture - especially film - can be used in the classroom to engage students in the pressing issues of global politics (Dodds, 2008; Swimelar, 2013; Van Munster \& Sylvester, 2013; Weber, 2005).

For me, the best work on visuality within a representative register is that which pays careful attention to existing work in film theory, semiotics and visual culture in order to produce the best accounts of how global politics makes itself felt visually. By 'best' I mean work that keeps the underlying political questions at the forefront of the discussion and doesn't descend into descriptive accounts and reductive significations (e.g. "...and then the aliens attacked, and that represents terrorism"). More generally, the best work within a visually attuned international political sociology understands that the representative register is entangled in our material worlds and thus cannot be held apart; indeed, it is the attachments between the representational and the political that count. There is, however, a lingering dissatisfaction with pursuing visual analyses primarily at the level of representation that has certainly led three of its primary architects - David Campbell, James Der Derian, and Cynthia Weber - to explore central political questions through more creative visual means (e.g. documentary film and photography). I think this is hugely exciting territory, especially for young scholars seeking to produce creative visual interventions into global politics.

\section{Site-Specific Seeing: The More-Than-Representational Register}

That lingering dissatisfaction with representational work is neatly summarized by Aida Hozić who wonders if there is 'a sense of fatigue with research focused on representation only' and suggests that studies remaining primarily at the representational level 'may no longer suffice' (2011: 169). I confess to being hugely taken with this shift, both intellectually and politically, because it offers a productive way out of what I considered to be the limitations of my own content-based work. Luckily, Gillian Rose's excellent book Visual Methodologies (2001) provides a helpful road-map out of that dissatisfaction by showing how content-based approaches can be adopted and transformed in site-specific institutional settings. Drawing largely on Foucauldian approaches, Rose shows how logics of seeing / being seen are also operative in particular social institutions such as museums where the configuration of things like architecture, objects and signage teaches visitors how to see, 
order and behave in the world. By shifting 'away from the details of individual images' - that is, from content analysis - Rose gets us to consider visuality in terms of 'the sites of production and audiencing, in their social modality' (2001: 167).

For IPS scholars working with visuality, this move has been enormously productive because it allows us to re-enter the material world with the same sophisticated interpretive skills we honed at the representational register. But more than that, it allows us to focus on the embodied, spatial and historically constituted nature of seeing and being seen in particular sites. To be sure, this has involved a great deal more transdisciplinary study on our part as we have been forced to engage with new intellectual ideas (e.g. theories of affect; corporeality; heterotopia; everyday life) and rethink our approach to traditional research methods. Indeed, one of the unexpected and welcome outcomes of this shift away from content-based visual research is a reinvigoration of our debates about research methods and methodology in general. To build on Hozić's insight: it feels somehow insufficient to ask only 'what is this image, what does it mean, and how is that significant?' We now have to ask much more difficult but ultimately rewarding questions about how the relations of seeing / being seen are constituted in the world as much as they are constituted in visual documents, and the extent to which those relations are enabled by entrenched formations of power. In short, we have been forced to figure out how to do visual research when looking is not restricted to images - when it is understood as part of the social relations that constitute us as subjects as well as the environments, infrastructures and landscapes we move through. Of course, the dominant asymmetries that constitute seeing / being seen relations within visual documents are similarly arranged within our material worlds: the challenge for scholars is to make those linkages explicit and use our expertise at content-based analysis to critically interrogate discrete political sites. Luckily for scholars working on visuality, this shift into the 'more-than-representational' has been enlivened by rewarding collaborations with critically-minded colleagues in sociology, anthropology and geography.

Certainly many of us followed Rose quite directly by exploring how pressing global issues have been mobilized visually, spatially, materially and politically in museums. Tim Luke, for example, showed very clearly how America's culture wars and anxieties over its post-Cold War global position were manifest in key museum exhibits (2002; see also Lisle, 2006b; Sylvester 2009). But for me, the most significant contribution that a visually attuned international political sociology has made so far is our careful and critical studies of borders and airports. While these sites were initially understood as explicit markers and performances of sovereign power, we quickly understood that seeing / being seen logics were integral to the way these forces produced, disaggregated and managed those seeking to cross borders. For example, these scholars have contributed to a wider transdisciplinary research agenda about surveillance by showing how multiple political authorities - especially the state - constitute themselves by an overwhelming capacity to locate, look at, survey and track populations. Not content to allow surveillance to remain invisible within the circuits of everyday life, these scholars have revealed how complex relationships between sovereignty, biopower, surveillance and space are mobilized in airport security transactions and border crossings (Adey, 2004, 2007, 2008; Bigo, 2006; Salter, 2007; 2008; Walters, 2006).

Certainly this work has been exemplary in the way it explores and works through contemporary social theory, most notably the insights of Foucault, Bourdiou and Agamben. Indeed, to suggest that these scholars simply 'apply' theoretical constructs to airports and borders does not do justice to the 
rich and textured insights that are mobilized here. This is because research dedicated to an international political sociology using non-representational accounts of visuality privileges the micropolitical and empirical nuances of border sites and excavates those with innovative research methods more familiar to sociologists, anthropologists and geographers (e.g. critical ethnographies; visual diaries; narrative accounts; go-alongs, participant observation). This has resulted in a research agenda that seeks to illustrate how deeper epistemological and ontological questions of visuality are harnessed to dominant power relations in very specific material and spatial sites - not just how these relations are produced, directed, encouraged and contained, but also how they pre-emptively empower privileged bodies and objects whilst simultaneously displacing deviant Others.

\section{Embodied and Entangled Seeing}

A number of scholars engaged in a visually attuned international political sociology in the morethan-representational register have confronted the limitations of a single binary logic of seeing / being seen. It is not just that bodies and objects are positioned within multiple fields of vision, it is also that the autonomy and separation of those entities - of seeing bodies and visualized objects - is no longer sacrosanct. I began to understand the deconstruction of the subject / object distinction so central to dominant accounts of visuality when analysing the stillness of one particular photograph of a Japanese POW during the Second World War (Lisle, 2010). What I realized was that the photograph itself had agency and made things happen: it triggered an affective response in the viewing subject that was unruly and potentially uncontainable. I stopped thinking of seeing subjects and viewed objects as separate and autonomous entities, and began to think relationally in ways that invoked ideas of networks, multiplicities, flows and connections. To put it another way, I understood that the central logic of seeing / being seen that had underscored so much of my previous visual analysis had to be made both heterogeneous and mobile. The result of this more expansive understanding of visuality has been a dramatic opening of both my research horizon (i.e. what I am seeing) and my research practices (i.e. how I am seeing and engaging with the world).

This shift in my personal research did not take place in isolation; indeed, this expansion has also characterized international political sociology scholarship on visuality more generally. By developing our careful micro-analyses well beyond specific sites like airports, we have realized that borders and the logics of visuality sequestered within them - have been redistributed, multiplied and intensified in numerous and often unexpected sites. In effect, by looking at the world in ways that do not reproduce a reductive subject / object distinction (or indeed, a singular and binary seeing / being seen logic), we are able to identify new productions, formations and relations of power. There is something very exciting about the uncontainabilty of this research; that is, scholars are more interested in tracing how power moves through chains of connection and multiplicity than they are in obeying familiar disciplinary categories (e.g. 'I study Africa', or 'I do security studies'). Think, for example, of the excellent transdisciplinary research that focuses on cities as sites of global politics: these are intensely networked spaces with multiple and highly mobile populations that must be surveilled, secured, controlled and managed on the one hand, and enabled to move, meet, flourish and produce on the other (Crang \& Graham, 2007; Lippert \& Murikami-Wood, 2012; Magnusson, 2011). These scholars do not understand cities as discrete or separate entities, but rather as globally connected, mobile and heterogeneous assemblages that are producing new ways of seeing, living and being towards the world. 
This expansion of the research agenda of an international political sociology is particularly energizing for scholars of visuality because it enables us to traverse the representational and nonrepresentational registers freely in order to demonstrate the multiple and complex manner in which images, visual technologies and practices of surveillance coalesce. One of the most important insights from scholars working within this expanded framework is how visuality has been deployed by various state and private authorities to govern everyday life in ways that normalize practices of surveillance and create new dispositions of watching. In other words, we are not just accustomed to being watched by various forms of 'Big Brother', we are also keen to watch each other on behalf of these authorities (Amoore, 2007; Andrejevic, 2004, 2006). Other scholars have approached visuality through materialism, technology and object analysis. Drawing on insights from Actor-Network Theory (ANT), Object-Oriented Ontology (OOO), Post-Humanism, New Materialism and especially Science, Technology and Society (STS), scholars are re-imagining how visuality is constituted within the vibrant connections of human/non-human assemblages. Geographers in particular have taken this one step further by reminding us that assemblages are also mobile; that is, the dominant structures of looking that seek to order people, things and ideas are constantly coming together, breaking apart and reassembling at very different speeds and scales. For example, recent work on verticality demonstrates how practices of surveillance do not just order the 'flattened' territory of sovereignty upon which we reside; rather, they also mobilize the prominent affective atmospheres that develop between the orbiting satellite and the earth-bound target (Adey, 2010; Adey et al, 2011; Anderson, 2009; Feldman, 2011). Drawing much more directly from New Materialism, other scholars of visuality focus specifically on how dominant ways of seeing have been directly shaped by technology and optics - an especially fruitful trajectory for those of us critically examining the entanglements between technology, visuality, killing and war (Gregory, 2011; Mirzoeff, 2011: 277310).

\section{Seeing the Global}

Certainly visuality is studied and developed in many different disciplines, not least in transdisciplinary centres of Visual Culture. But what I think scholars dedicated to connecting the international, the political and the sociological contribute to this conversation is the vital claim that visuality is always already global; that is, even the most intimate and domestic seeing / being seen relations are constituted in a chain of entanglements that have geopolitical significance. Our particular area of expertise is showing how those chains of structured seeing mobilize, refract and re-distribute existing asymmetries of power. Our challenge is to find new scholars unpacking the layers of globalization and visuality in different ways so we can enliven our conversations about the political significance of seeing and being seen.

It is clear from this account of visuality that I have moved away from the representational register into more embodied, entangled and mobile relations of seeing. By this I do not mean to denigrate or forget the importance of work at the representational level; indeed this is often my starting point into larger questions and puzzles. And while overly descriptive accounts of visual products continue to enrage me (especially when description is a stand-in for critical analysis), my own challenge is to find ways of looping between the representational and non-representational registers without losing the political or global significance of the larger issues at stake. It is for this reason that I am most excited by those developments within an international political sociology that include visuality both 
implicitly and explicitly in new methodological improvisations, developments and innovations (Salter \& Mutlu, 2012; Aradau et al, 2014).

\section{REFERENCES:}

Adey, Peter (2004) 'Surveillance at the Airport: surveilling mobility / mobilizing surveillance', Environment and Planning A: 36(8): 1365-1380.

Adey, Peter (2007) 'May I Have Your Attention: Airport Geographies of Spectatorship, Position and (Im)mobility', Environment and Planning D, 25(3): 515-536.

Adey, Peter (2008) 'Aeromobilities: Geographies, Subjects and Vision', Geography Compass, 2(5): 1318-1336.

Adey, Peter (2010) 'Vertical Security in the Megacity: Legibility, Mobility and Aerial Politics', Theory, Culture and Society, 27(6): 51-67.

Adey, Peter; Whitehead, Mark; and Williams, Alison J. (2011) 'Air-Target: Distance, Reach and the Politics of Verticality', Theory, Culture and Society, 28(7-8): 173-187.

Amoore, Louise (2007) 'Vigilant Visualities: The Watchful Politics of the War on Terror', Security Dialogue, 38(2): 139-156.

Amoore, Louise (2009) 'Lines of Sight: The Visualization of Unknown Futures', Citizenship Studies, 13(1): $17-30$

Anderson, Ben (2009) 'Affective Atmospheres', Emotion, Space and Society, 2(2): 77-81.

Andrejevic, Mark (2004) 'The Work of Watching One Another: Lateral Surveillance, Risk and Governance' Surveillance and Society, 2(4): 479-497.

Andrejevic, Mark (2006) 'The Discipline of Watching: Detection, risk, and Lateral Surveillance', Critical Studies in Media Communication, 23(5): 391-407.

Aradau, Claudia; Huysmans, Jef; Neal, Andrew; and Voelkner, Nadine; Eds. (2014) Critical Security Methods: New Frameworks for Analysis. London: Routledge.

Aradau, Claudia and van Munster, Rens (2012) Politics of Catastrophe: Genealogies of the Unknown. London: Routledge.

Bigo, Didier (2006) 'Security, Exception, Ban and Surveillance', Ch. 3 in David Lyon, Ed., Theorizing Surveillance: The Panopticon and Beyond. London: Routledge.

Bissell, David (2009) 'Visualising Everyday Geographies: practices of vision through travel-time', Transactions of the Institute of British Geographers, 34(1): 42-60.

Bleiker, Roland (2001) 'The Aesthetic Turn in International Political Theory', Millennium, 30(3): 509533.

Bleiker, Roland (2009) Aesthetics and World Politics. Houndmills: Palgrave MacMillan. 
Butler, Judith (2010) Frames of War: When is Life Grievable? London: Verso.

Campbell, David (1992) Writing Security: United States Foreign Policy and the Politics of Identity. Minneapolis: University of Minnesota Press.

Campbell, David (2007) 'Geopolitics and Visuality: Sighting the Darfur Conflict', Political Geography, 26(4): 357-382.

Crang, Mike (1997) 'Picturing Practices: research through the tourist gaze' Progress in Human Geography, 21(3): 359-373.

Crang, Mike \& Graham, Stephen (2007) 'Sentient Cities: Ambient Intelligence and the Politics of Urban Space', Information, Communication \& Society, 10(6): 789-817.

Danchev, Alex (2009) On Art and War and Terror. Edinburgh: Edinburgh University Press.

Dauphinée, Elizabeth (2007) 'The Politics of the Body in Pain: Reading the Ethics of Imagery', Security Dialogue, 38(2): 139-155.

Der Derian, James \& Shapiro, Michael J. (1989) International / Intertextual Relations: Postmodern Readings of World Politics. Lexington, MA: Lexington Books.

Dodds, Klaus (2008) 'Have You Seen Any Good Films Lately? Geopolitics, International Relations and Film', Geography Compass, 2(2): 476-494.

Feldman, Keith P. (2011) 'Empire's Verticality: The Af/Pak Frontier, Visual Culture, and Racialization from Above', Comparative American Studies, 9(4): 325-341.

Graham, Steve (2010) 'Combat Zones that See: Urban Warfare and US Military Technology', pp. 199223 in Fraser McDonald, Rachel Hughes and Klaus Dodds, eds., Observant States: Geopolitics and Visual Culture. London: I.B. Tauris.

Gregory, Derek (2011) 'From a View to a Kill: Drones in Late Modern War', Theory, Culture and Society, 28(7-8): 188-215.

Grondin, David (2011) 'The Other Spaces of War: War beyond the Battlefield in the War on Terror', Geopolitics, 16(2): 253-279.

Hansen, Lene (2011) 'Theorizing the Image for Security Studies: Visual Securitization and the Muhammad Cartoon Crisis', European Journal of International Relations, 17(1): 51-74.

Hozić, Aida (2011) 'Visuality and Geopolitics', Political Geography, 30(3): 169-172.

Hughes, Rachel (2007) 'Through the Looking Blast: Geopolitics and Visual Culture' Geography Compass, 1(5): 976-994.

Hutchinson, Emma (2014) 'A Global Politics of Pity? Disaster Imagery and the Emotional Construction of Solidarity after the 2004 Asian Tsunami' International Political Sociology, 8(1): 1-19.

Jay, Martin (1994) Downcast Eyes: The Denigration of Vision in Twentieth-Century French Thought. Berkeley: University of California Press. 
Kiersey, Nicholas J. \& Neumann, Iver B. (2013) Battlestar Galactica and International Relations. London: Routledge.

Landau, Paul \& Kaspin, Deborah, Eds. (2002) Images and Empires: Visuality in Colonial and Postcolonial Africa. Berkeley: University of California Press.

Lippert, Randy \& Murikami-Wood, David (2012) 'The New Urban Surveillance: Technology, Mobility, and Diversity in $21^{\text {st }}$ Century Cities', Surveillance and Society, 9(3): 257-262.

Lisle, Debbie (2006a) The Global Politics of Contemporary Travel Writing. Cambridge: Cambridge University Press.

Lisle, Debbie (2006b) 'Sublime Lessons: Education and Ambivalence in War Exhibitions', Millennium, 34(3): 185-206.

Lisle, Debbie (2007) 'Benevolent Patriotism: Art, Dissent and the American Effect', Security Dialogue, 38(2): 233-250.

Lisle, Debbie (2010) 'Moving Encounters: the Affective Mobilities of Photography', pp. 139-154 in David Bissell \& Gillian Fuller, Eds., Stillness in a Mobile World. London: Routledge.

Luke, Timothey W. (2002) Museum Politics: Power Plays at the Exhibition. Minneapolis: University of Minnesota Press.

MacDonald, Fraser; Hughes, Rachel \& Dodds, Klaus J., Eds. (2010) Observant States: Geopolitics and Visual Culture. London: I.B. Tauris.

Magnusson, Warren (2011) The Politics of Urbanism: Seeing Like a City. London: Routledge.

Mirzoeff, Nicholas (2011) The Right to Look: A Counterhistory of Visuality. Durham, NC: Duke University Press.

Möller, Frank (2010) 'Rwanda Revisualized: Genocide, Photography and the Era of the Witness', Alternatives, 35(2): 113-136.

Möller, Frank (2013) Visual Peace: Images, Spectatorship and the Politics of Violence. Houndmills: Palgrave MacMillan.

Pratt, Mary Louise (1992) Imperial Eyes: Travel Writing and Transculturation. London: Routledge.

Rancière, Jacques (2009) Dissensus: on Politics and Aesthetics, Trans. Steven Corcoran. London: Continuum.

Rancière, Jacques (2006) The Politics of Aesthetics, Trans. Gabriel Rockhill. London: Continuum.

Rose, Gillian (2001) Visual Methodologies. London: Sage.

Ryan, James (1997) Picturing Empire: Photography and the Visualization of British Empire. Chicago: University of Chicago Press. 
Salter, Mark B. (2007) 'Governmentalities of an Airport: Heterotopia and Confession', International Political Sociology, 1(1): 49-66.

Salter, Mark B. (2008) Politics at the Airport. Minneapolis: University of Minnesota Press.

Salter, Mark B. \& Mutlu, Can, Eds. (2012) Research Methods in Critical Security Studies: An Introduction. London: Routledge.

Shapiro, Michael J., Ed. (1984) Language and Politics. Oxford: Wiley Blackwell.

Shapiro, Michael J.(1988) The Politics of Representation: Writing Practices in Biography, Photography and Policy Analysis. Madison: University of Wisconsin Press.

Shapiro, Michael J. (2008) Cinematic Geopolitics. London: Routledge.

Shim, David (2013) Visual Politics and North Korea: Seeing is Believing. London: Routledge.

Swimelar, Saphia (2013) 'Visualizing International Relations: Assessing Student Learning Through Film', International Studies Perspectives, 14(1): 14-38.

Sylvester, Christine (2009) Art / Museums: International Relations Where We Least Expect It. Boulder: Paradigm.

Van Munster, Rens \& Sylvester, Casper (2013) 'Documenting International Relations: Documentary Film and the Creative Arrangement of Perceptibility', International Studies Perspectives, DOI $24^{\text {th }}$ Sept.

Walters, William (2006) 'Border/Control', European Journal of Social Theory, 9(2): 187-203.

Weber, Cynthia (1995) Simulating Sovereignty: Intervention, the State and Symbolic Exchange. Cambridge: Cambridge University Press.

Weber, Cynthia (2005) Imagining America at War: Morality, Politics and Film. London: Routledge.

Weldes, Jutta, Ed. (2003) To Seek Out New Worlds: Exploring Links Between Science Fiction and World Politics. Houndmills: Palgrave MacMillan.

Williams, Michael (2003) 'Words, Images, Enemies: Securitization and International Politics', International Studies Quarterly, 47(4): 511-531.

\footnotetext{
${ }^{1}$ Of course, this is only part of the story of how in International Relations, for instance, the emerging field of international political sociology came into being (indeed, as we know, origin stories are always partial and incomplete). There were many scholars, especially Didier Bigo and Rob Walker, whose energy and commitment opened up important institutional spaces within which our ideas could flourish.

${ }^{2}$ This is not to suggest that scholars working on visual representations are always accepted by mainstream IR and welcomed into the discipline as equal partners. Certainly many of us have encountered difficulties when speaking to those gate-keepers who want to marginalize the very purpose of our intellectual projects as 'irrelevant' or 'not IR' or 'not rigorous enough'. What I am suggesting here is that compared to even a decade ago there are more intellectual spaces within which these conversations about visuality can develop without the requisite methodological justifications, and there are also more institutional opportunities to pursue visually-based scholarship within an international political sociology.
} 